\title{
Synthesis of Nanocrystalline Boron Carbide by Direct Microwave Carbothermal Reduction of Boric Acid
}

\author{
Rodolfo F. K. Gunnewiek, Pollyane M. Souto, and Ruth H. G. A. Kiminami \\ Department of Materials Engineering, Federal University of São Carlos, Rod. Washington Luiz, km 235, \\ 13565-905 São Carlos, SP, Brazil
}

Correspondence should be addressed to Rodolfo F. K. Gunnewiek; rodolfo.foster@unifal-mg.edu.br

Received 24 January 2017; Accepted 12 March 2017; Published 27 March 2017

Academic Editor: Stefano Bellucci

Copyright (c) 2017 Rodolfo F. K. Gunnewiek et al. This is an open access article distributed under the Creative Commons Attribution License, which permits unrestricted use, distribution, and reproduction in any medium, provided the original work is properly cited.

\begin{abstract}
The excellent physical and chemical properties of boron carbide make it suitable for many applications. However, its synthesis requires a large amount of energy and is time-consuming. Microwave carbothermal reduction is a fast technique for producing well crystallized equiaxial boron carbide nanoparticles of about $50 \mathrm{~nm}$ and very few amounts of elongated nanoparticles were also synthesized. They presented an average length of $82 \mathrm{~nm}$ and a high aspect ratio (5.5). The total reaction time was only 20 minutes, which disfavor the growing process, leading to the synthesis of nanoparticles. Microwave-assisted synthesis leaded to producing boron-rich boron carbide. Increasing the forward power increases the boron content and enhances the efficiency of the reaction, resulting in better crystallized boron carbide.
\end{abstract}

\section{Introduction}

Boron carbide is covalent carbide, which presents some of the best physical and chemical properties. $\mathrm{B}_{4} \mathrm{C}$ is the third hardest material and shows high Young's modulus, high melting point $\left(2450^{\circ} \mathrm{C}\right.$ without decomposing), excellent chemical resistance, very low density $\left(2.52 \mathrm{~g} / \mathrm{cm}^{3}\right)$, low stiffness, excellent thermoelectric properties, and good cross section absorption of thermal neutrons. These properties make it suitable for numerous applications from wear resistant components and cutting tools to high temperature thermocouples and neutron absorbers [1-5]. Boron carbide can also be used as a precursor or reduction agent to produce boron nitride and transition-metal diborides $\left(\mathrm{TiB}_{2}, \mathrm{ZrB}_{2}, \mathrm{HfB}_{2}\right.$, and $\left.\mathrm{CrB}_{2}\right)[6-$ 10] and recently has been applied in gamma ray scintillator and neutron detectors and as high efficiency thermoelectric material $[11,12]$.

It belongs to the rhombohedral lattice $\mathrm{R} \overline{\mathrm{B}} \mathrm{m}$ space group, although a recent paper describes a second $\mathrm{B}_{4} \mathrm{C}$ phase with monoclinic structure, reopening the discussion about the boron carbide structure [13]. Boron carbide can be found in a wide range of carbon and boron compositions: from $\mathrm{B}_{11.4} \mathrm{C}$ (with 8\%-at. of carbon) to the most well-known $\mathrm{B}_{4} \mathrm{C}$ (with 20\%-at. of carbon) and even high carbon content boron carbide $\mathrm{B}_{11.4} \mathrm{C}_{3.6}\left(\mathrm{~B}_{3.17} \mathrm{C}\right)$, which corresponds to $24 \%$-at. of carbon $[2,14-16]$. The composition of boron carbide affects its properties, since carbon-rich crystals approach the ideal crystal and have the lowest electrical conductivity, while boron-rich crystals are more resistant to radiation damage. However, the ideal boron carbide structure, $\mathrm{B}_{4} \mathrm{C}$, is composed of $\mathrm{B}_{11} \mathrm{C}$ icosahedra and $\mathrm{C}-\mathrm{B}-\mathrm{C}$ chains comprising the longest diagonal in the rhombohedral structure [2].

Boron carbide can be synthesized by different methods, for example, magnesiothermic and aluminothermic reduction, both of which are exothermic reductions of $\mathrm{B}_{2} \mathrm{O}_{3}$ in the presence of metallic magnesium or aluminum, and a carbon source [2, 16-18], vapor phase reaction [2], polymer precursors [17, 19-22], liquid phase reaction [23], and solid state reaction [15] are other alternative routes to producing boron carbide. The carbothermal reduction, a technique widely used in industry and laboratory to produce mostly carbides, including boron carbide, consists of reacting an oxide (boron oxide) and a carbon source at high temperatures, which normally takes several hours to complete [2].

An inexpensive and efficient way to synthesize boron carbide by the aforementioned technique is using boric acid 


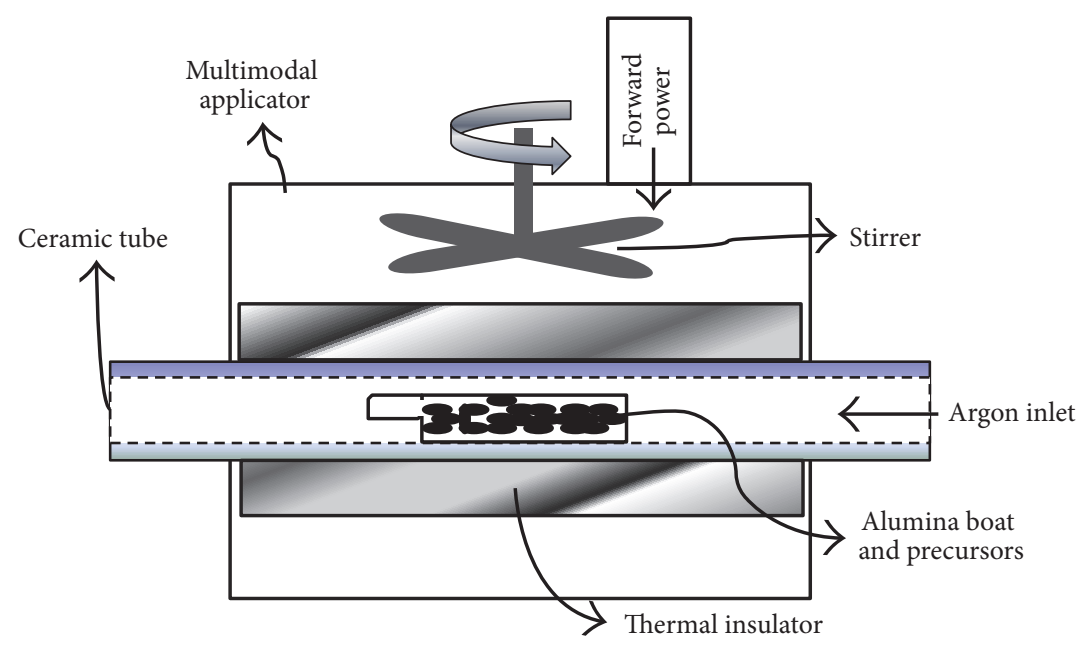

FIGURE 1: Schematic diagram of the microwave reaction system.

and carbon black or charcoal as starting materials [24-28]. The general reaction between boric acid and carbon is very simple: first the boric acid dehydrates and is converted to boron anhydride, followed by the reduction to elemental boron by carbon, and finally the reaction of this species with carbon, yielding boron carbide. This reaction is efficient and pure boron carbide can be produced at temperatures above $1400^{\circ} \mathrm{C}$ and normally a long reaction time ( $1 \mathrm{~h}$ to $5 \mathrm{~h}$ ) [2]. The reaction time and temperature, heating rate, and boron/carbon rate are essential parameters to control the final average particles size. Increasing both the reaction time and temperature enhances $\mathrm{B}_{4} \mathrm{C}$ synthesis [25]. Higher heating rates cause the raw materials to reach the final temperature rapidly, practically without undergoing an intermediate temperature. Higher temperature favors reactions in the vapor state and high levels of nucleation, which can result in finer particles.

Finer nanoparticles are hard to synthesize, because, besides the high nucleation rate caused by high temperature, the particles growing is also observed due the long reaction time. This factor can be avoided by the use of microwaves, which reduces considerably the time and prevents excessive particle growth. Hard materials such as $\mathrm{TiC}, \mathrm{TaC}, \mathrm{WC}$, nanometric titanium carbide, and carbonitride have been produced by microwave irradiation [29-33].

Nitrides and carbides are very difficult to sintering due to their reduced diffusion coefficients. The use of nanostructured boron carbide can enhance the sintering, because the diffusion is accelerated due to the high surface energy, also leading to obtaining ceramics with controlled and finer microstructure (the benefits of finer microstructure in the properties (e.g., mechanical, electrical, and others) are well known). The sintering step is influenced by the initial boron carbide particle size and shape and also by additives, such as free carbon, which prevents the formation of boron oxide thin film [34] and a low melting point at the grain boundary, aiding mass diffusion and also controlling grain growth [17].

This paper describes a fast and efficient approach for preparing nanocrystalline $\mathrm{B}_{4} \mathrm{C}$ by microwave carbothermal reduction of boric acid. Microwave forward power, which influences the synthesis of boron carbide, is also evaluated for both stoichiometric and hyperstoichiometric raw materials.

\section{Experimental Procedures}

Disordered carbon black with high surface area $\left(263.2 \mathrm{~m}^{2} / \mathrm{g}\right)$ and pure boric acid (Merck, >99\%) were used in this experiment. The raw materials, at a ratio of $4: 7 \mathrm{~mol}$ of boric acid/carbon (R4B), were suspended in ethanol (the boric acid dissolved completely) and stirred continuously on a hot plate at $50^{\circ} \mathrm{C}$ for one hour to partially evaporate the solvent, which rendered the suspension pasty. The partially dried paste was extruded into pellets and completely dried in a kiln at around $50^{\circ} \mathrm{C}$ (this procedure was necessary to prevent the removal of the precursors by the argon flux during the reaction). In addition, to determine whether it is possible to synthesize high boron-content boron carbide, another precursor was prepared with a boric acid to carbon ratio of $8: 7(\mathrm{R} 8 \mathrm{~B})$. About $2 \mathrm{~g}$ of the pellets was spread on a small alumina/mullite boat (50 mm in length) and placed in a microwave oven $(2.45 \mathrm{GHz}$, Cober, USA), whose reaction chamber was cleaned for $10 \mathrm{~min}$ with an argon flow set at $1.0 \mathrm{~L} / \mathrm{min}$. The reaction systems were designed to protect the oven and control the atmosphere, as depicted in Figure 1. The reaction system consisted in a low porosity ceramic tube coated with refractory fiber (to avoid heat loss) placed inside the oven cavity. An argon inlet was connected to the tube at one end and a gas collector at the other. The rectangular boat crucible containing the precursor was inserted into the tube at the center of the oven cavity.

The microwave forward power was set at 1.8 and $2.1 \mathrm{~kW}$ for each composition. The samples were allowed to cool in an argon atmosphere to prevent reoxidation, which took no more than $40 \mathrm{~min}$. The cooled powders were deagglomerated and ground in a mortar and sifted through a 325-mesh sieve. To determine the phase constitution, X-ray diffraction (XRD) patterns of the powders were recorded in a Siemens D5005 diffractometer using copper $\mathrm{K} \alpha$ radiation $(\lambda=1,5406 \AA)$. Crystallite size $d$ was calculated using Scherrer's relation 


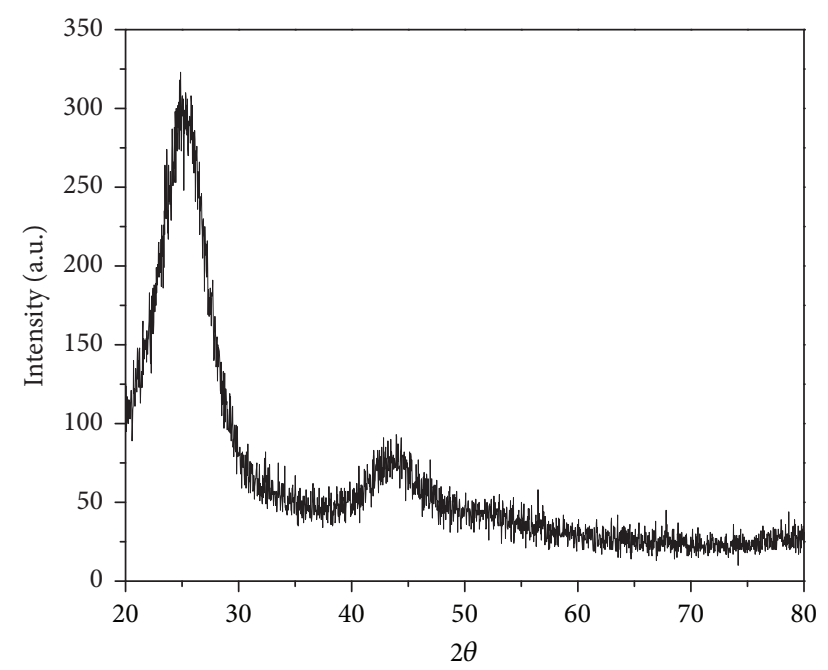

FIGURE 2: X-ray diffractogram of disordered carbon black used in this work.

shown in (1), where $\theta$ is the Bragg angle and $B$ is the sample line broadening at full-width at half maximum (FWHM), which is the relation between the experimental FWHM and the instrumental correction.

$$
d=\frac{0.9 \lambda}{B \cos \theta} \text {. }
$$

The microstructure of the powders was characterized by field emission gun scanning electron microscopy (FEG-SEM) (Philips XL30 FEG) at $25 \mathrm{kV}$ and by transmission electron microscopy (TEM) (TECNAI G2F20).

\section{Results and Discussion}

Figure 2 depicts the X-ray diffractogram of the carbon black used in this work, revealing that it is composed of two bands at $2 \theta$ of around $20-30^{\circ}$ and $40-50^{\circ}$, corresponding to a disordered material.

Disordered carbon black showed a high dielectric loss tangent, $\tan \delta$, from 0.35 to 0.83 [36], which makes it a good microwave absorber, interacting strongly with the microwave electric field, promoting the high heating very rapidly to the temperatures at which the reactions occur. Moreover, the pelletization process ensures that a sufficiently porous microstructure is obtained, enabling the first gaseous product of the reaction, water, to be released when boric acid begins to dehydrate around $80^{\circ} \mathrm{C}$ and continues up to $330^{\circ} \mathrm{C}$ [37]. The $\mathrm{B}_{2} \mathrm{O}_{3}$ melts at around $450^{\circ} \mathrm{C}$. Furthermore, the $\mathrm{B}_{2} \mathrm{O}_{3}$ obtained in this first carbon reduction step is still in close contact with the particles of carbon black. Thus, the entire carbothermal reduction reaction took only $20 \mathrm{~min}$, followed by $40 \mathrm{~min}$ of cooling, after which the diffractograms were recorded.

Figures 3(a) and 3(b) depict the diffractograms of powders R4B 1 and 2 and R8B 1 and 2 (the notation 1 or 2 corresponds to the microwave power level used in the synthesis: 1.8 or $2.1 \mathrm{~kW}$, resp.). These images clearly show the influence of the boron content and forward power on the synthesis of boron carbide. At a low boric acid content (Figure 3(a)) (proportion of $4: 7$ of $\mathrm{H}_{3} \mathrm{BO}_{3} / \mathrm{C}$ ), the formation of boron carbide is evident, and the well-defined peaks in the XRD pattern are very clear. The peaks correspond to rhombohedral $\mathrm{B}_{4} \mathrm{C}$ for R4B-1 and R4B-2 and are consistent with JCPDS card number 35-798, although smaller peaks corresponding to unreacted orthoboric acid, $\mathrm{H}_{3} \mathrm{BO}_{3}$, and a band of disordered carbon were detected. Moreover, the intensity of the peaks increased along with the power level, possibly indicating more crystalline boron carbide and/or more effective reaction, yielding a larger total amount of boron carbide when synthesized at higher power. When the boric acid content in the precursor was doubled, the reaction could not be completed, so practically only boric acid peaks and disordered bands are visible. Nevertheless, there are small peaks corresponding to JCPDS card number 86-1126 (Figure 3(b)), that is, boron-rich boron carbide $\left(\mathrm{B}_{13.38} \mathrm{C}_{1.62}\right)$, suggesting the presence of traces of this hyperstoichiometric boron carbide. We believe the reaction could not occur with this large amount of boric acid for the following reasons: (1) After the raw materials are mixed and then dried, the boric acid (or melted dehydrated boron oxide) forms a very thick layer on the carbon particles, hindering the mass diffusion and, hence, the full formation of boron carbide. This may explain the very low percentage of possible high boron-content boron carbide. (2) The high content of $\mathrm{B}_{2} \mathrm{O}_{3}$ after dehydration reacted to free carbon, forming carbon monoxide and dioxide and $\mathrm{B}_{2} \mathrm{O}_{2}$, which consumed most of the carbon and yielded boron oxide (which rehydrated to form boric acid), a small amount of hyperstoichiometric boron carbide, and a very minor amount of unreacted carbon, which decreased as the forward power increased.

Lower power leads to a lower reaction temperature. This effect is evident by comparing the peaks of the two samples; that is, the peaks of sample R4B-1 were less intense than those of sample R4B-2, and the crystalline peaks increased considerably in response to higher power. Sample R4B-2 showed more evident peaks, even when the peak was not relevant, providing evidence of well crystallized rhombohedral $\mathrm{B}_{4} \mathrm{C}$ at a higher power of $2.1 \mathrm{~kW}$, while sample R4B-1 synthesized at a lower power $(1.8 \mathrm{~kW})$ presented only the main significant diffraction peaks corresponding to the hexagonal planes (104) and (021).

Broadening of the main peak suggests very fine particles. In fact, by applying Scherrer's relation (1) to the main peak, plane (021), the average crystallite size can be inferred and, as expected, this broadening of peaks is a sign of the presence of nanoparticles of $50.5 \mathrm{~nm}$ in the R4B-1 powder and slightly larger ones of $57.1 \mathrm{~nm}$ in the R4B-2 powder.

The rhombohedral lattice can also be described as a hexagonal lattice [38], and, in the case of $\mathrm{B}_{4} \mathrm{C}$, the hexagonal $c_{\mathrm{H}}$ axis is parallel to the longest diagonal of the rhombohedral structure, which contains the three-atom chain (C-B-C). Table 1 summarizes the calculated hexagonal and rhombohedral lattice parameters and the theoretical lattice parameters of stoichiometric $\mathrm{B}_{4} \mathrm{C}$ (JCPDS card number 35-798). Many authors have described changes in lattice parameters as a function of carbon and boron content in unitary cells, stating that the lattice parameters increase when hyperstoichiometric boron carbide (boron-rich) is obtained [12, 15, 35, 39]. Our 
TABLE 1: Lattice parameters of as-synthesized boron carbide at different levels of forward power.

\begin{tabular}{lccccc}
\hline & $\begin{array}{c}a_{\mathrm{H}} \\
(\mathrm{nm})\end{array}$ & $\begin{array}{c}c_{\mathrm{H}} \\
(\mathrm{nm})\end{array}$ & $\begin{array}{c}a_{\mathrm{R}} \\
(\mathrm{nm})\end{array}$ & $\begin{array}{c}\alpha \\
(\text { degrees })\end{array}$ & $\begin{array}{c}\text { Cell volume } \\
\left.(\mathrm{nm})^{3}\right)\end{array}$ \\
\hline R4B-1 $(1.8 \mathrm{~kW})$ & 0.5596 & 1.2061 & 0.5158 & 65.7053 & 0.2114 \\
R4B-2 $(2.1 \mathrm{~kW})$ & 0.5600 & 1.2070 & 0.5162 & 65.7081 & 0.2117 \\
Stoichiometric $\mathrm{B}_{4} \mathrm{C}$ (theoretical) & 0.5600 & 1.2086 & 0.5166 & 65.6486 & 0.2118 \\
\hline
\end{tabular}

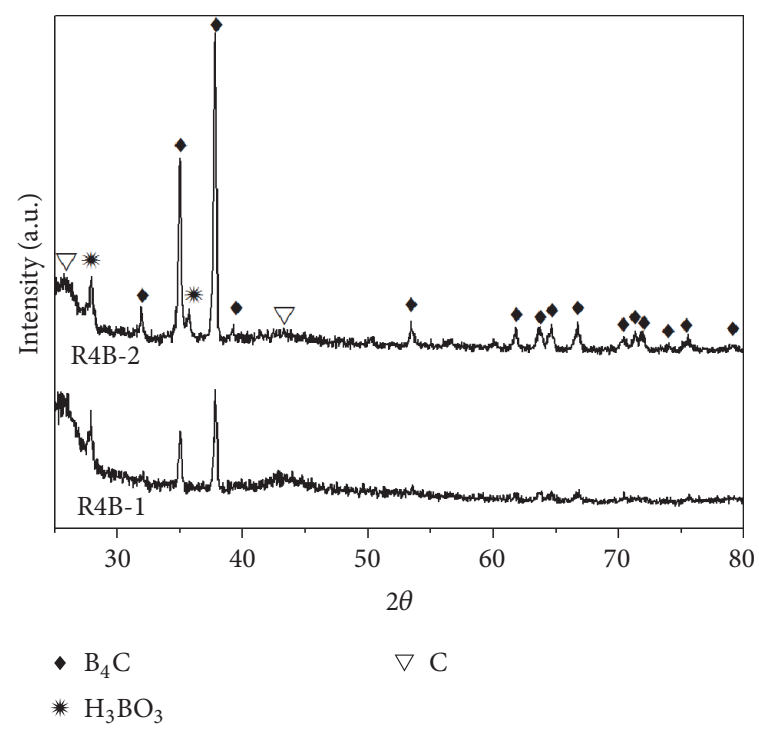

(a)

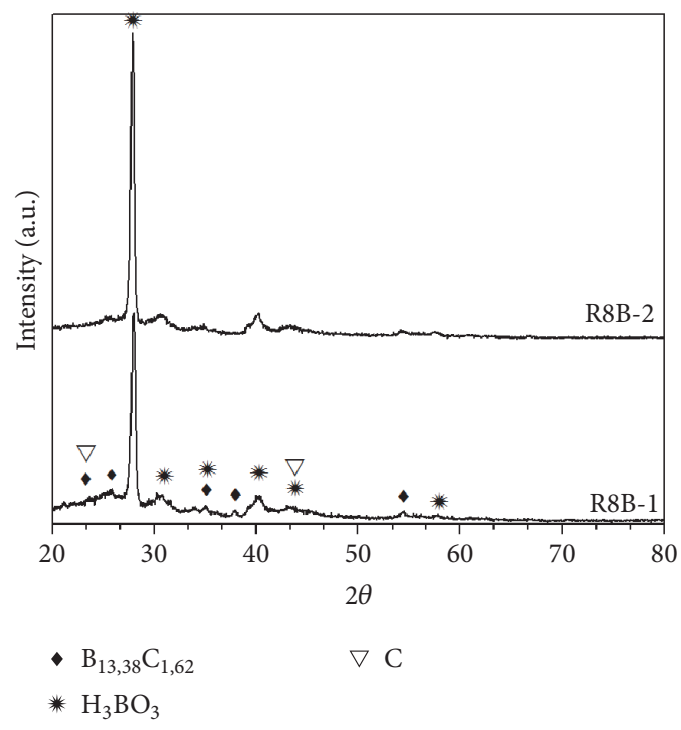

(b)

FIGURE 3: XRD patterns of R4B (a) and R8B (b) powders reacted at different power levels: $1.8 \mathrm{~kW}$ (R4B-1 and R8B-1) and 2.1 kW (R4B-2 and R8B-2), obtained in only 20 min of reaction, showing crystalline boron carbide synthesis.

experiments showed a very clear change in lattice parameters, suggesting differences in the amounts of boron and carbon as a function of microwave power and, in the R $8 \mathrm{~B}$ series, of the boron content in raw materials. Higher forward power leads to enriching the lattice with boron, since the expansion of lattice parameters is observed, particularly on the $c_{\mathrm{H}}$ axis. The possible explanation is the higher temperatures and higher heating rates achieved under higher power levels, which favors the reaction between boron suboxides and free carbon, yielding hyperstoichiometric boron carbide [2].

Many authors $[12,15,35,39]$ have described the relationship between the atomic percentage of carbon and the lattice parameters of boron carbide. The contraction of the lattice parameters suggests an increase in the carbon content of the lattice up to given values of $c_{\mathrm{H}}$ and $a_{\mathrm{H}}$. Aselage and Tissot [15] and Gosset and Colin [35] reported three changes in the slope of $c_{\mathrm{H}}$ : linear fitted between $1.217 \mathrm{~nm}$ and $1.206 \mathrm{~nm}$ and two additional slopes, one below and the other above this range. Werheit and Shalamberidze [39] reported a maximum $c_{\mathrm{H}}$ at around $1.219 \mathrm{~nm}$, which decreased to a lower (boronrich) and higher (carbon-rich) $\mathcal{c}_{\mathrm{H}}$ value.

The carbon content (\%-at) was estimated by fitting the second slope (Figure 4) between $1.217 \mathrm{~nm}$ and $1.206 \mathrm{~nm}$ to the curves described by both Aselage and Tissot (A\&T) and Gosset and Colin (G\&C). The A\&T fitting of sample R4B-1 showed a carbon content of $20.37 \%$-at, while the G\&C fitting yielded $18.51 \%$-at. These values correspond to the chemical formulas $\mathrm{B}_{4.91} \mathrm{C}$ and $\mathrm{B}_{5.40} \mathrm{C}$, respectively. The carbon content decreased slightly in response to increasing power input. In the case of sample R4B-2, which was synthesized at $2.1 \mathrm{~kW}$, the A\&T fitting yielded a carbon content of $19.81 \%$-at, while the G\&C fitting yielded $18.13 \%$-at, corresponding to the chemical formulas $\mathrm{B}_{5.05} \mathrm{C}$ and $\mathrm{B}_{5.51} \mathrm{C}$, respectively.

At about $2 \theta$ of $26^{\circ}$, an amorphous pattern is visible, which corresponds to unreacted carbon and is more evident in the diffractogram of sample R4B-1. The peak intensity ratio of $\mathrm{B}_{4} \mathrm{C}$ [22] can be estimated from the relation of $\mathrm{B}_{4} \mathrm{C}$ and amorphous band intensities, as indicated in the following:

$$
R=\frac{I_{\mathrm{B}_{4} \mathrm{C}}}{\left(I_{\mathrm{B}_{4} \mathrm{C}}+I_{\mathrm{C}}\right)} .
$$

The peak intensity ratios calculated for R4B-1 and R4B2 are 0.51 and 0.79 , respectively, which means there is more unreacted carbon when the precursors are subjected to lower microwave power, $1.8 \mathrm{~kW}$. However, boron carbide can be synthesized at even lower power. Increasing the power accelerated the heating rate due to the excellent microwave absorption capacity of carbon, and therefore the temperature reached in the reaction was higher. However, the best condition for this reaction was not attained at lower power. The remaining free carbon seems to be beneficial for 
TABLE 2: Reaction parameters and results of microwave carbothermal reaction.

\begin{tabular}{lcccc}
\hline Sample & $\begin{array}{c}\text { Reaction time } \\
(\mathrm{min})\end{array}$ & $\begin{array}{c}\text { Power } \\
(\mathrm{kW})\end{array}$ & $\begin{array}{c}\text { Average crystallite size } \\
(\mathrm{nm})\end{array}$ & $\begin{array}{c}\text { Corresponding chemical } \\
\text { formula }(\mathrm{A} \& \mathrm{~T})\end{array}$ \\
\hline $\mathrm{R} 4 \mathrm{~B}-1$ & 20 & 1.8 & 50.5 & $\mathrm{~B}_{4.91} \mathrm{C}$ \\
$\mathrm{R} 4 \mathrm{~B}-2$ & 20 & 2.1 & 57.1 & $\mathrm{~B}_{5.05} \mathrm{C}$ \\
\hline
\end{tabular}

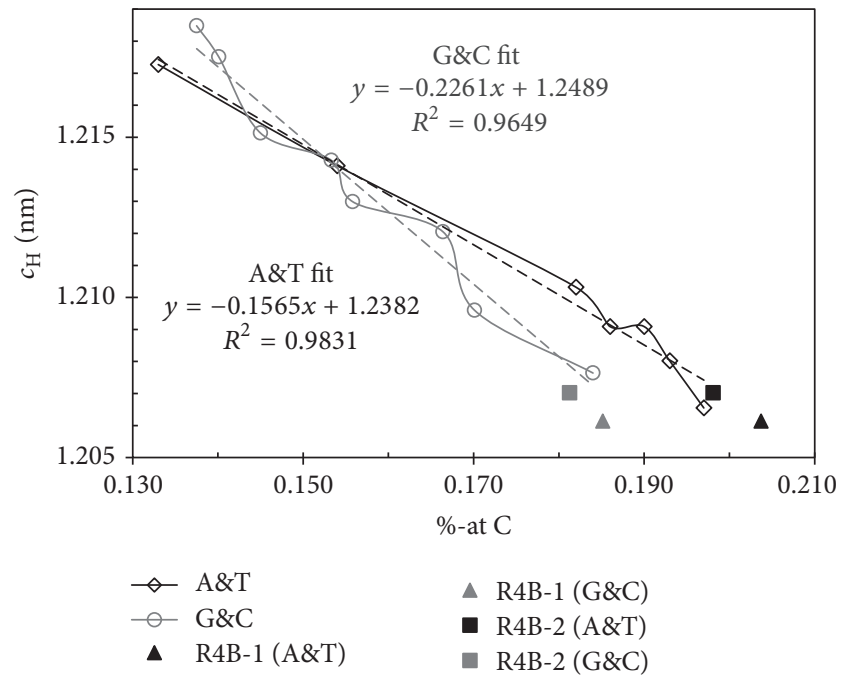

FIGURE 4: Values reported in the literature for the hexagonal $c$ lattice parameter as a function of carbon content, and plot of values of samples R4B-1 and R4B-2 calculated by Aselage and Tissot (A\&T) [15] and Gosset and Colin (G\&C) [35] by second slope fitting.

further sintering of the material, since it can enhance the mass diffusion at the grain boundaries [17].

Owing to its high heating rate and efficient energy transfer, the microwave-induced reaction led to synthesis and yielded fine boron carbide particles. SEM images (Figures 5(a) and 5(b)) show homogeneous boron carbide powders synthesized using microwave radiation. Figure 5(a) shows R4B-1 SEM powder morphology and Figure 5(b) shows the R4B-2 powder morphology after microwave-assisted carbothermal reduction in only 20 minutes of reaction. Samples R4B-1 and R4B-2 both presented a homogeneous morphology with average particle sizes of 75 and $80 \mathrm{~nm}$, respectively. Equivalent $\mathrm{B}_{4} \mathrm{C}$ nanopowders were synthesized once by conventional heating, but the process took 5 hours [40]. Figures 5(a) and 5(b) also show some aggregates. We believe this structure is formed early during the low temperature reaction step, when boron oxide probably melts, yielding some clusters which will be reduced by carbon, forming the cited structure. Jung et al. [26] identified the formation of clusters at very low temperature of about $700^{\circ} \mathrm{C}$.

The SEM micrographs of the powders show equiaxial nanoparticles (Figure 6(a)). The average size of the equiaxial particles, calculated from TEM micrographs, is $47.1 \mathrm{~nm}$, little below the average crystallite size. The electron diffraction pattern of R4B-2 in Figure 6(a) shows very well crystallized $\mathrm{B}_{4} \mathrm{C}$, confirming the XRD analysis. According to Jung et al. [26], the equiaxial nanoparticles are synthesized mostly by solid-liquid reaction. However, a detailed TEM micrograph of the R4B-2 powder (Figure 6(b)) reveals the presence of not only the aforementioned equiaxial nanoparticles but also an uncommon presence of elongated nanorod primary particles, with an average length of $81.5 \mathrm{~nm}$ and aspect ratio of 5.5. The presence of these particles is very rare. Even covering the entire extension of TEM grid, the aforementioned morphology was found punctually. They might be synthesized in nonstoichiometric regions with low carbon content (boronrich) and are often synthesized when the reactants are in the gaseous state [26].

Table 2 summarizes the reaction parameters and results of boron carbide nanopowders. A very short reaction time of 20 min under microwave irradiation leads to the formation of nanostructured $\mathrm{B}_{4} \mathrm{C}$ of equivalent average size at both microwave power levels, with the reaction efficiency and crystallization enhanced at higher power.

The use of microwave radiation is highly favorable for both solid-liquid and gas-solid reactions. Vaporized boron oxide can be carried out by other gases, such as carbon monoxide and argon flux, which may change the stoichiometry of the reaction and lead to an incomplete reaction, leaving behind free carbon. Higher temperatures favor the evaporation of boron oxide, according to Herth et al. [27], who calculated that its vaporization rate at $1300^{\circ} \mathrm{C}$ is $6.2 \mathrm{~nm} / \mathrm{s}$. This means that, in 20 minutes of reaction, most of the boron oxide will evaporate and can react with carbon particles via solid-gas or can be carried out by others gases. It is stated that fast microwave heating is advantageous in synthesizing nanosized boron carbide without causing changes in the $\mathrm{C} / \mathrm{H}_{3} \mathrm{BO}_{3}$ precursors, resulting in chemical compositions close to the well-known rhombohedral $\mathrm{B}_{4} \mathrm{C}$. According to Weimer et al. [24], higher heating rates combined with high temperatures favor the formation of boron carbide clusters via the reaction of $\mathrm{C}_{(\mathrm{s})}$ or $\mathrm{CO}_{(\mathrm{g})}$ with gas-phase boron oxide, yielding primary particles smaller than $100 \mathrm{~nm}$.

As discussed early, the reaction can take place in three steps: (1) boric acid dehydrates at temperatures above $80^{\circ} \mathrm{C}$, transforming to boron anhydride $\left(\mathrm{B}_{2} \mathrm{O}_{3}\right),(2)$ boron oxide is reduced by carbon producing elementary boron, and (3) the reaction between elementary boron and carbon forms boron carbide.

Upon completion of the first step of $\mathrm{B}_{2} \mathrm{O}_{3}$ formation, the kinetics of microwave carbothermal reduction probably begins with the solid-liquid reaction of melted $\mathrm{B}_{2} \mathrm{O}_{3}$ with solid carbon, directly producing equiaxial boron carbide, while the solid-gas reaction of carbon with evaporated $\mathrm{B}_{2} \mathrm{O}_{3}$ forms it directly or via reduction of boron oxide and reaction with the elementary boron. An intermediary reaction step may occur, forming boron suboxide $\mathrm{B}_{2} \mathrm{O}_{2}$, which is highly volatile. This can help the gaseous reaction. Microwave 


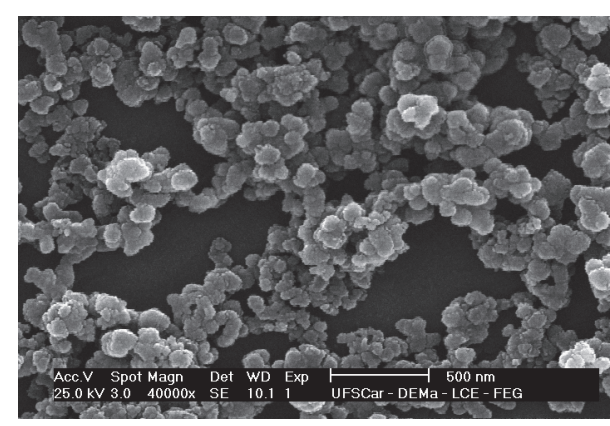

(a)

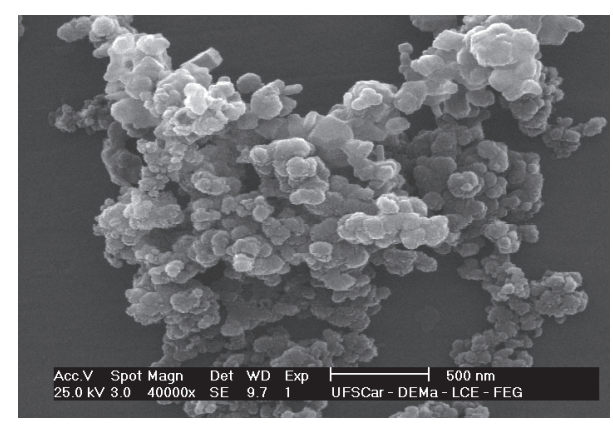

(b)

FIGURE 5: SEM micrographs of (a) R4B-1 and (b) R4B-2. The nanoparticles were synthesized using microwaves as the heating source.

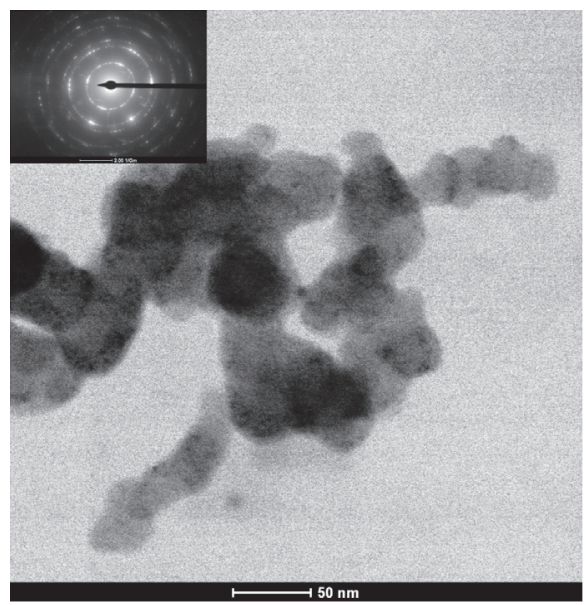

(a)

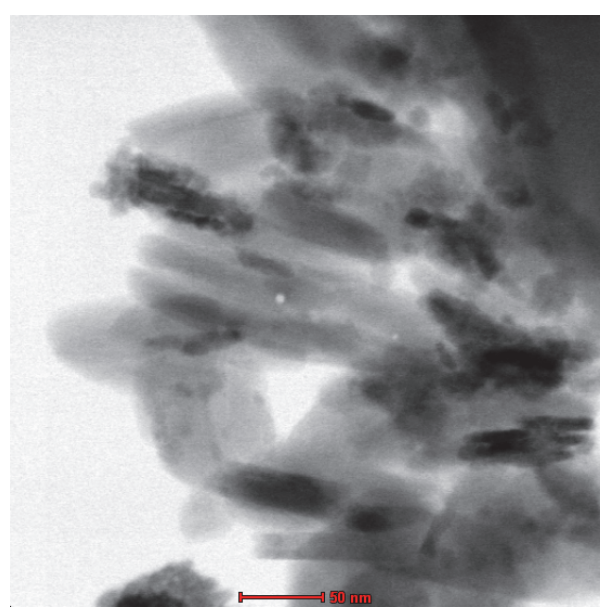

(b)

FIGURE 6: TEM images of R4B-2: (a) details of the morphology of equiaxial nanoparticles and ED pattern with crystalline $\mathrm{B}_{4} \mathrm{C}$ and $(\mathrm{b})$ equiaxial and rare presence of elongated morphology.

power promotes high heating rates above the vaporization temperature of boron oxide, and most of it goes to the vapor phase, which is reduced by carbon, forming boron suboxide and $\mathrm{CO}_{(\mathrm{g})}$. The suboxide, still in the vapor phase, forms boron carbide by reacting with carbon and/or carbon monoxide. On the other hand, $\mathrm{B}_{2} \mathrm{O}_{2}$ may be carried away by the argon flux, interfering in the efficiency of the reaction. The solidgas reaction of $\mathrm{B}_{2} \mathrm{O}_{3}$ is more probable, according to the calculation of Gibb's free energy performed by Herth et al. [27]. It is believed that direct reduction by both solid-liquid and solid-gas reactions of carbon and $\mathrm{B}_{2} \mathrm{O}_{3}$ occurred more probably.

The efficient energy transfer favored by microwave processing, especially because of excellent absorption capacity of carbon black, enabled boron carbide to synthesize rapidly without any additive such as magnesium or aluminum or even a catalyst such as cobalt. At the temperature of reaction, there is a competition between the kinetic processes of nucleation of new particles and growing, wherein the last is favored. The efficient energy transfer to carbon black leads to high heating rates and fast synthesis, which can contribute to fine particles, since the growing step is disfavored by the short dwell time at high temperature. However, a high boron oxide ratio (R8B) is not effective for synthesis, because boron oxide probably reacts with carbon, forming carbon monoxide and volatile $\mathrm{B}_{2} \mathrm{O}_{2}$. This reaction consumes the carbon or causes the boron oxide to melt around the carbon particles, hindering mass diffusion and preventing the effectiveness of the reaction. Moreover, the partial reduction of boron oxide to volatile $\mathrm{B}_{2} \mathrm{O}_{2}$ occurs even at a higher carbon ratio, which is one of the reasons for the presence of residual unreacted carbon [26], which can be carried away by the argon flux. Another factor is the short reaction time, which is described by many authors [26, 28, 41], as well as temperature, which is critical in the synthesis of boron carbide.

Carbothermal reduction is advantageous to synthesize equiaxial boron carbide nanoparticles. The use of microwave power as a heating source proved to be efficient to synthesize well crystallized nanostructured boron carbide. It avoided excessive loss of the boron oxide at high heating rates (or higher temperatures) as pointed by many authors [20, $24,26,27]$, maintaining the reaction close to the planed stoichiometry. Moreover, this process is simple and economically attractive, involving the use of inexpensive precursors 
and reducing production time, since boron carbide can be obtained in only 20 minutes of reaction time.

\section{Conclusions}

Microwave carbothermal reduction is fast and effective for synthesizing well crystallized nanostructured equiaxial boron carbide, starting with inexpensive and simple precursors such as boric acid and carbon black, without any reaction agent as magnesium or aluminum, or cobalt as catalyst. A short reaction time of only $20 \mathrm{~min}$ under microwave irradiation is required to synthesize boron carbide, but the reaction is sensitive to the power level and precursors content. Increasing the boric acid proportion (R8B 1 and 2), the reactivity falls drastically and traces of hyperstoichiometric boron carbide are observed. On the other hand, higher power levels lead to well crystallized particles, with increasing in boron content, as inferred by variation in the lattice parameters.

The synthesis at higher power level $(2.1 \mathrm{~kW})$ yielded very well crystallized nanometric boron carbide phase, according to our X-ray diffraction analysis. The SEM micrographs revealed particles of around $80 \mathrm{~nm}$ forming aggregates. The TEM micrographs revealed the presence of equiaxial particles with an average size of about $50 \mathrm{~nm}$. However, very rare elongated particles are also found, which reinforce the inference of both solid-liquid and solid-gas reactions, promoted by microwave-assisted synthesis.

\section{Conflicts of Interest}

The authors declare that there are no conflicts of interest regarding the publication of this paper.

\section{Acknowledgments}

The authors acknowledge the financial support of the Brazilian research funding agencies FAPESP (Proc. 07/59564-0) and CNPq (Proc. 142911/2009-7).

\section{References}

[1] H. O. Pierson, Handbook of Refractory Carbide and NitridesProperties, Characteristics, Processing and Applications, Noyes Publications, Saddle River, NJ, USA, 1st edition, 1996.

[2] A. K. Suri, C. Subramanian, J. K. Sonber, and T. S. R. Ch Murthy, "Synthesis and consolidation of boron carbide: a review," International Materials Reviews, vol. 55, no. 1, pp. 4-38, 2010.

[3] V. Domnich, S. Reynaud, R. A. Haber, and M. Chhowalla, "Boron carbide: structure, properties, and stability under stress," Journal of the American Ceramic Society, vol. 94, no. 11, pp. 3605-3628, 2011.

[4] F. Thévenot, "Boron carbide-a comprehensive review," Journal of the European Ceramic Society, vol. 6, no. 4, pp. 205-225, 1990.

[5] A. S. Kipcak, P. Gurses, E. M. Derun, N. Tugrul, and S. Piskin, "Characterization of boron carbide particles and its shielding behavior against neutron radiation," Energy Conversion and Management, vol. 72, pp. 39-44, 2013.

[6] G. J. Zhang, M. Ando, J. F. Yang, T. Ohji, and S. Kanzaki, "Boron carbide and nitride as reactants for in situ synthesis of boride-containing ceramic composites," Journal of the European Ceramic Society, vol. 24, no. 2, pp. 171-178, 2004.

[7] C. Subramanian, T. S. R. C. Murthy, and A. K. Suri, "Synthesis and consolidation of titanium diboride," International Journal of Refractory Metals and Hard Materials, vol. 25, no. 4, pp. 345350, 2007.

[8] W. G. Fahrenholtz, G. E. Hilmas, I. G. Talmy, and J. A. Zaykoski, "Refractory diborides of zirconium and hafnium," Journal of the American Ceramic Society, vol. 90, no. 5, pp. 1347-1364, 2007.

[9] J. K. Sonber, T. S. R. Ch. Murthy, C. Subramanian, S. Kumar, R. K. Fotedar, and A. K. Suri, "Investigations on synthesis of $\mathrm{HfB}_{2}$ and development of a new composite with $\mathrm{TiSi}_{2}$," International Journal of Refractory Metals and Hard Materials, vol. 28, no. 2, pp. 201-210, 2010.

[10] J. K. Sonber, T. S. R. C. Murthy, C. Subramanian, S. Kumar, R. K. Fotedar, and A. K. Suri, "Investigation on synthesis, pressureless sintering and hot pressing of chromium diboride," International Journal of Refractory Metals and Hard Materials, vol. 27, no. 5, pp. 912-918, 2009.

[11] Y. Ben-Galim, U. Wengrowicz, A. Raveh, and I. Orion, "Gamma scintillator system using boron carbide for neutron detection," Nuclear Instruments and Methods in Physics Research, Section A: Accelerators, Spectrometers, Detectors and Associated Equipment, vol. 756, pp. 62-67, 2014.

[12] S. Roszeitis, B. Feng, H.-P. Martin, and A. Michaelis, "Reactive sintering process and thermoelectric properties of boron rich boron carbides," Journal of the European Ceramic Society, vol. 34, no. 2, pp. 327-336, 2014.

[13] W. P. Huhn and M. Widom, "A free energy model of boron carbide," Journal of Statistical Physics, vol. 150, no. 3, pp. 432441, 2013.

[14] S. V. Konovalikhin and V. I. Ponomarev, "Carbon in boron carbide: The crystal structure of $\mathrm{B}_{11.4} \mathrm{C}_{3.6}$," Russian Journal of Inorganic Chemistry, vol. 54, no. 2, pp. 197-203, 2009.

[15] T. L. Aselage and R. G. Tissot, "Lattice constants of boron carbides," Journal of the American Ceramic Society, vol. 75, no. 8, pp. 2207-2212, 1992.

[16] V. I. Ponomarev, I. D. Kovalev, S. V. Konovalikhin, and V. I. Vershinnikov, "Ordering of carbon atoms in boron carbide structure," Crystallography Reports, vol. 58, no. 3, pp. 422-426, 2013.

[17] A. Sinha, T. Mahata, and B. P. Sharma, "Carbothermal route for preparation of boron carbide powder from boric acid-citric acid gel precursor," Journal of Nuclear Materials, vol. 301, no. 2-3, pp. 165-169, 2002.

[18] L. Zhang, Y. Gu, W. Wang et al., "A fast-pyrolysis self-propagating high temperature synthesis route to single phase of boron carbide ultrafine powders," Journal of the Ceramic Society of Japan, vol. 119, no. 1392, pp. 631-634, 2011.

[19] S. Mondal and A. K. Banthia, "Low-temperature synthetic route for boron carbide," Journal of the European Ceramic Society, vol. 25, no. 2-3, pp. 287-291, 2005.

[20] I. Yanase, R. Ogawara, and H. Kobayashi, "Synthesis of boron carbide powder from polyvinyl borate precursor," Materials Letters, vol. 63, no. 1, pp. 91-93, 2009.

[21] M. Kakiage, N. Tahara, I. Yanase, and H. Kobayashi, "Lowtemperature synthesis of boron carbide powder from condensed boric acid-glycerin product," Materials Letters, vol. 65, no. 12, pp. 1839-1841, 2011.

[22] M. Kakiage, Y. Tominaga, I. Yanase, and H. Kobayashi, "Synthesis of boron carbide powder in relation to composition and 
structural homogeneity of precursor using condensed boric acid-polyol product," Powder Technology, vol. 221, pp. 257-263, 2012.

[23] Y. Gu, L. Chen, Y. Qian, W. Zhang, and J. Ma, "Synthesis of nanocrystalline boron carbide via a solvothermal reduction of $\mathrm{CCl}_{4}$ in the presence of amorphous boron powder," Journal of the American Ceramic Society, vol. 88, no. 1, pp. 225-227, 2005.

[24] A. W. Weimer, W. G. Moore, R. P. Roach, J. E. Hitt, R. S. Dixit, and S. E. Pratsinis, "Kinetics of carbothermal reduction synthesis of boron carbide," Journal of the American Ceramic Society, vol. 75, no. 9, pp. 2509-2514, 1992.

[25] A. Alizadeh, E. Taheri-Nassaj, and N. Ehsani, "Synthesis of boron carbide powder by a carbothermic reduction method," Journal of the European Ceramic Society, vol. 24, no. 10-11, pp. 3227-3234, 2004.

[26] C.-H. Jung, M.-J. Lee, and C.-J. Kim, "Preparation of carbonfree $\mathrm{B}_{4} \mathrm{C}$ powder from $\mathrm{B}_{2} \mathrm{O}_{3}$ oxide by carbothermal reduction process," Materials Letters, vol. 58, no. 5, pp. 609-614, 2004.

[27] S. Herth, W. J. Joost, R. H. Doremus, and R. W. Siegel, "New approach to the synthesis of nanocrystalline boron carbide," Journal of Nanoscience and Nanotechnology, vol. 6, no. 4, pp. 954-959, 2006.

[28] T. Kobayashi, K. Yoshida, and T. Yano, "Effects of addition of seed grains on morphology and yield of boron carbide powder synthesized by carbothermal reduction," Ceramics International, vol. 39, no. 4, pp. 3849-3856, 2013.

[29] N. A. Hassine, J. G. P. Binner, and T. E. Cross, "Synthesis of refractory metal carbide powders via microwave carbothermal reduction," International Journal of Refractory Metals and Hard Materials, vol. 13, no. 6, pp. 353-358, 1995.

[30] K. Essaki, E. J. Rees, and G. T. Burstein, "Synthesis of nanoparticulate tungsten carbide under microwave irradiation," Journal of the American Ceramic Society, vol. 93, no. 3, pp. 692-695, 2010.

[31] H. Zhang, F. Li, Q. Jia, and G. Ye, "Preparation of titanium carbide powders by sol-gel and microwave carbothermal reduction methods at low temperature," Journal of Sol-Gel Science and Technology, vol. 46, no. 2, pp. 217-222, 2008.

[32] R. F. K. Gunnewiek, P. M. Souto, and R. H. G. A. Kiminami, "Microwave-assisted synthesis of $\mathrm{TiC}$ by carbothermal reduction," in Processing and Properties of Advanced Ceramicsand Composites IV_Ceramics Transactions, J. P. Singh, N. P. Bansal, T. Goto et al., Eds., vol. 234, pp. 93-98, John Wiley \& Sons, Hoboken, NJ, USA, 2012.

[33] R. F. K. Gunnewiek, P. M. Souto, and R. H. G. A. Kiminami, "Microwave-assisted synthesis of TiCN by carbothermal reduction," in Proceedings of the 13th International Conference on Microwave and RF Heating, J. Tao, Ed., pp. 205-208, Toulouse, France, 2011.

[34] M. A. Rossi, M. J. Matthewson, A. Kaza, D. Niesz, and R. L. Haber, "Modeling of gas-phase transport and composition evolution during the initial-stage sintering of boron carbide with carbon additions," Journal of the American Ceramic Society, vol. 93, no. 11, pp. 3691-3699, 2010.

[35] D. Gosset and M. Colin, "Boron carbides of various compositions: an improved method for X-rays characterisation," Journal of Nuclear Materials, vol. 183, no. 3, pp. 161-173, 1991.

[36] J. A. Menéndez, A. Arenillas, B. Fidalgo et al., "Microwave heating processes involving carbon materials," Fuel Processing Technology, vol. 91, no. 1, pp. 1-8, 2010.
[37] S. Balc1, N. A. Sezgi, and E. Eren, "Boron oxide production kinetics using boric acid as raw material," Industrial \& Engineering Chemistry Research, vol. 51, no. 34, pp. 11091-11096, 2012.

[38] B. D. Cullity, Elements of X-Ray Diffraction, Addison-Wesley, Reading, Mass, USA, 2nd edition, 1978.

[39] H. Werheit and S. Shalamberidze, "Advanced microstructure of boron carbide," Journal of Physics Condensed Matter, vol. 24, no. 38, Article ID 385406, 2012.

[40] H. Zeng, Y.-M. Kan, and G.-J. Zhang, "Synthesis of boron carbide powder from hexagonal boron nitride," Materials Letters, vol. 64, no. 18, pp. 2000-2002, 2010.

[41] N. Tahara, M. Kakiage, I. Yanase, and H. Kobayashi, "Effect of addition of tartaric acid on synthesis of boron carbide powder from condensed boric acid-glycerin product," Journal of Alloys and Compounds, vol. 573, pp. 58-64, 2013. 

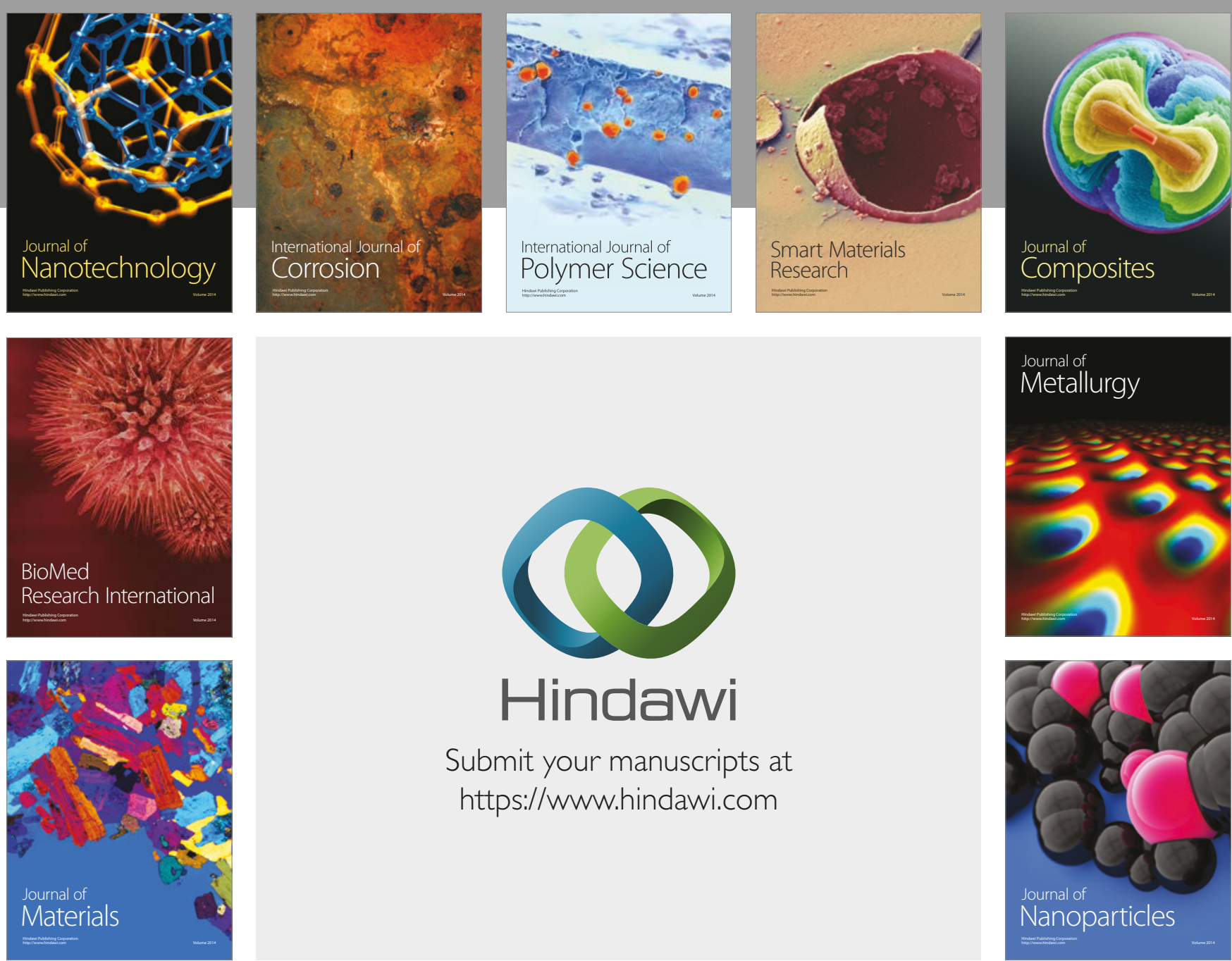

\section{Hindawi}

Submit your manuscripts at

https://www.hindawi.com
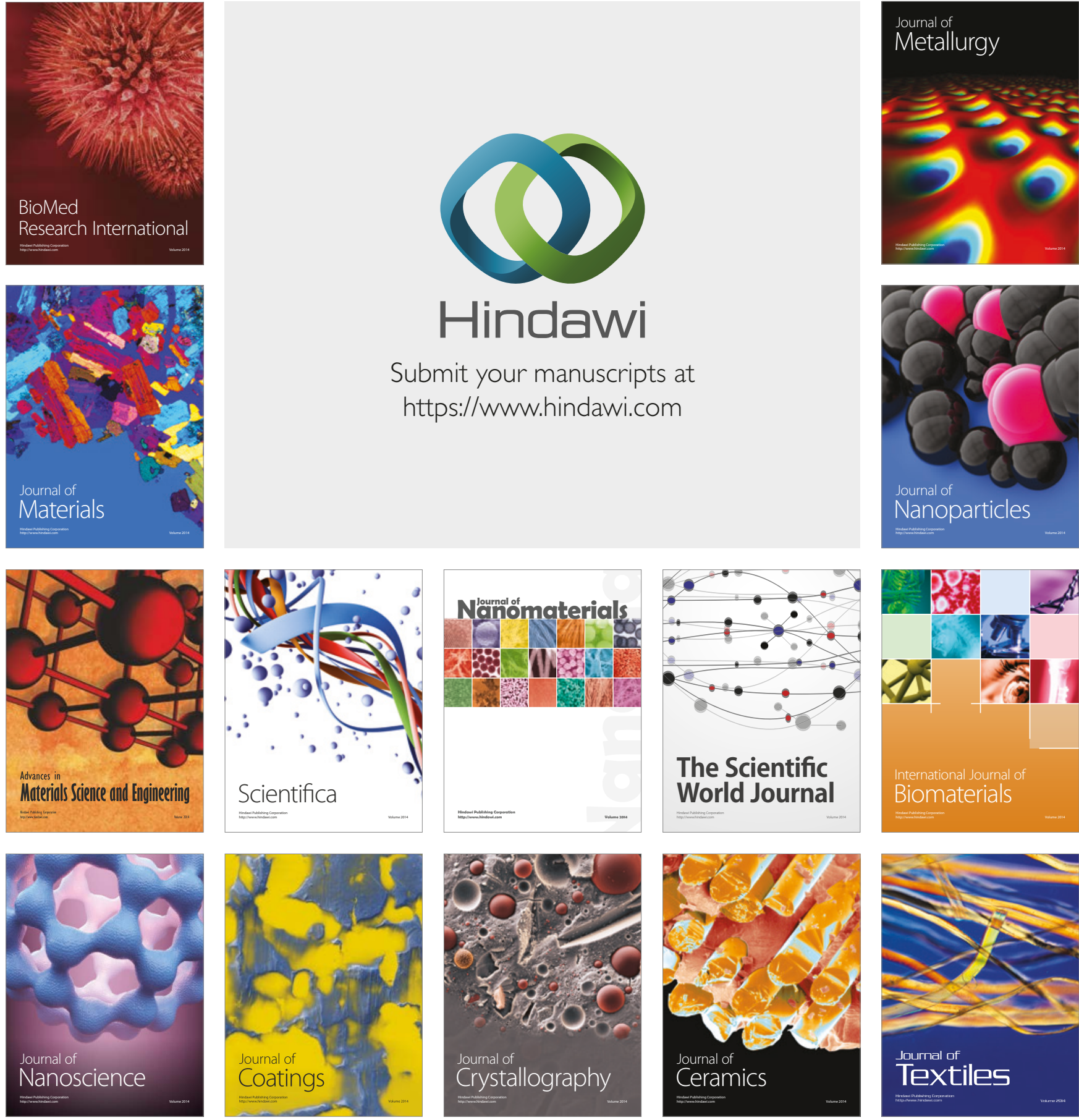

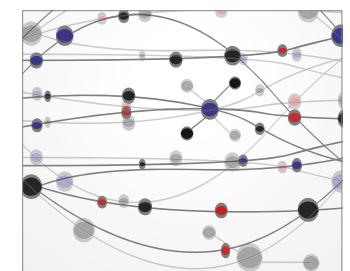

The Scientific World Journal
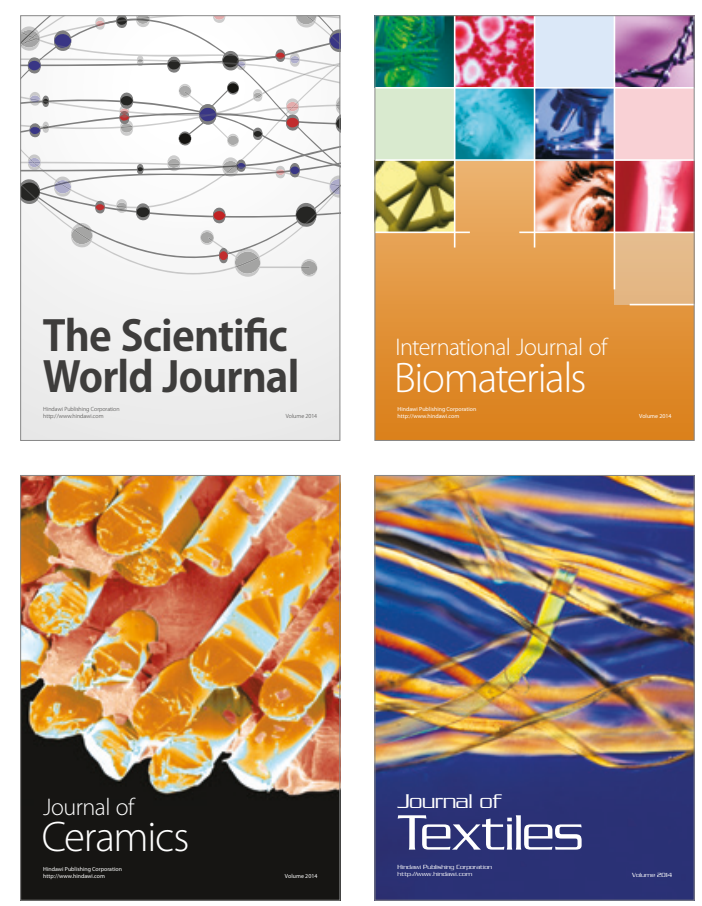